\title{
ENTREVISTA COM MARK DAVID RIDD
}

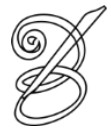 \\ Sátia Marini ${ }^{1}$ \\ (Mestra em Estudos da Tradução - POSTRAD-UnB/Brasília/DF/Brasil) \\ smarini@mgnetdf.com.br \\ Patrícia Rodrigues Costa ${ }^{2}$ \\ (Mestra em Estudos da Tradução - POSTRAD-UnB/Brasília/DF/Brasil) \\ prcosta1986@gmail.com
}

$\mathrm{M}$ ark David Ridd é professor de Tradução na Universidade de Brasília desde 1986. Esse inglês nasceu em Buenos Aires quando seu pai era diplomata naquele país. Suas aulas são tão divertidas quanto instrutivas, com pitadas de um humor próprio dele. Curioso sobre ornitologia, com habilidades ao piano, esse tradutor tem muitas histórias para contar sobre a profissão. É uma pena não podermos reproduzir todo o conteúdo aqui, pois a entrevista está imperdível. Duas palavras para descrever sua relação com a tradução? Paixão e fúria.

Para começar, uma curiosidade. O que o levou a ser tradutor? E como descobriu que queria ser professor?

MARK DAVID RIDD Eu acho que eu me tornei tradutor muito por acidente. Fiz uma matéria optativa na escola chamada "estudos clássicos", que era basicamente latim e grego. Estávamos lendo um livro, o "Livro Sexto" da Eneida, e eu e um colega notamos que estávamos sempre preenchendo lacunas, porque o livro era uma sequência e a gente dependia muito do que tinha acontecido no livro anterior, que a gente não tinha lido. Estudamos então por conta própria, pegamos o livro em latim e traduzimos. Acho que começou um pouco por aí. Aqui no Brasil um amigo que estava num aperto para traduzir um livro me convidou para fazer uma parte. Comecei a ver o outro lado da tradução, totalmente diferente. Quando fui para a Inglaterra fazer doutorado me pediram para traduzir um texto do Fernando Henrique [Cardoso] sobre democratização. Ele tem um texto difícil. Me esforcei bastante nessa tradução, e quando me pagaram, recebi mais do que o combinado. Entrei em contato achando que tinha tido um erro e me disseram que não, que tinham dinheiro reservado para a tradução e havia sobrado, então decidiram premiar as traduções que gostaram mais. Recebi uns 
duzentos dólares a mais. Voltei ao Brasil, deixei meu currículo na Fundação Visconde de Cabo Frio, no Itamaraty, e comecei a trabalhar bastante em eventos, só com tradução. Traduzia basicamente do português para o inglês, mas acabei traduzindo também entre português e espanhol e inglês, em função dos eventos. Melhorei muito meu português traduzindo do inglês para o português também. Já professor era a única coisa que eu sabia que eu não queria fazer como carreira. Quando estava terminando a escola, meu tutor perguntou se eu não pensava em ser professor. Eu disse "não, nunca, prefiro ser lixeiro antes de ser professor". E seis meses depois eu estava em sala de aula. Mas aos poucos fui vendo que era uma coisa quase como cachaça, né? Era o extremo contrário do que eu achei que seria ser professor: achei que seria extremamente desagradável. À medida que você vai lecionando, você toma gosto. Depois, fui fazer doutorado em Literatura Comparada em Londres, justamente pensando em uma carreira universitária como professor de Literatura. Lecionei literatura inglesa no CEUB. Quando abriu uma vaga na UnB, em 1986, era para Tradução. Eu já traduzia, mas não tinha formação ou vida acadêmica na área. Pensei: "estando dentro da porta posso lecionar isso por um tempo e depois mudar para literatura." No ano seguinte abriu um concurso para uma vaga efetiva como professor de Tradução e aí eu já estava totalmente mordido pelo bicho da tradução e não pensei mais em ser professor de Literatura. E eu podia lecionar tradução literária e boa parte da teoria usava exemplificação do texto literário; foi uma transição bastante natural. Comecei traduzindo essencialmente textos políticos, administrativos, no Itamaraty, discursos, documentos para reuniões ad hoc, cobrindo eventos multilaterais. Na universidade tive contato com professores de outras áreas, áreas que eu tinha zero de conhecimento: odontologia, desenvolvimento de plantas para gripe. Fiz traduções de vídeos, quase sempre institucionais ou documentais. Depois traduzi poesia. Tenho feito isso em alguns ambientes profissionais também. Realmente tenho tido uma vida muito variada e isso é uma coisa muito boa na minha vida profissional. Ter essa variedade de experiência fora da sala de aula alimenta muito bem a sala de aula. Lecionei todas as disciplinas de prática, tanto obrigatória quanto optativa, e isso também me ajudou. A experiência que você tem em uma área acaba tendo reflexos nas outras. Durante muito tempo até fui favorável a que todo professor fizesse rodízio entre as disciplinas, porque era uma alimentação por áreas contíguas. 
Qual a importância da prática no ensino e na atividade acadêmica e das teorias da tradução nas atividades práticas de tradutores profissionais?

MARK DAVID RIDD: As duas coisas não funcionam muito bem sozinhas. A teoria só faz sentido para o aluno se ele tem alguma experiência prática própria para contrastar ou usar como parâmetro para julgar as teorias. O contrário também, a prática só funciona bem quando associada à reflexão. Talvez o nome "teoria" seja infeliz, porque teoria sugere algo que precede e é necessário para algo prático e, no caso da tradução, é exatamente o contrário, a prática precede muito a teorização, e em termos de teorização sistemática tem quase dois mil anos de antecedência. Além do mais, durante os séculos a prática prescindiu da teoria, então ela não é uma atividade necessariamente prévia para fazer tradução. No curso de formação, a teoria deve ser o local da reflexão, pois cria uma atitude crítica do aluno e o expõe a diferentes ideias sobre tradução. Fazer tradução é lidar com uma proliferação de decisões que têm que ser tomadas quase que simultaneamente em muitos níveis bem diferentes, que às vezes parecem não ter nada a ver com a atividade. Isso é estimulante do ponto de vista como tradutor e tento despertar no aluno a sensação de que você está sendo constantemente desafiado a tomar decisões. O que importa para um aluno de tradução é que ele tenha capacidade de tomar decisões mais conscientemente, de se dar mais opções do que alguém que aprende exclusivamente na prática. Ao contrário do que parece ser bom senso, o bom tradutor se dá mais trabalho, se faz pensar em mais opções e possíveis tomadas de decisão do que entrar em um módulo de piloto automático. Isso distingue o excelente tradutor do tradutor médio. Um dos nossos erros em termos de história no curso é que a teoria sempre foi vista como precedente: primeiro se estudava teoria, depois as práticas. Uma das preocupações nas reformas curriculares tem sido tentar criar uma infiltração maior entre as duas áreas. Cabe ao professor de teoria mostrar para o aluno como as ideias trabalhadas afetam de forma concreta a atividade de tradução. Cabe ao professor de prática fazer a ligação entre um problema concreto que surge em sala de aula e ideias, reflexões a respeito da tradução que nascem da teoria. A teoria funciona melhor com o aluno quando surge naturalmente de problemas pontuais.

O que você acha dessa exigência de só no final do curso os alunos fazerem estágio em tradução fora da UnB?

MARK DAVID RIDD: Bem, isso obviamente tem dois lados. Do ponto de vista do aluno, quanto mais estágio melhor, porque ele não está só praticando, mas praticando para valer em 
alguma empresa que vai ter uso efetivo e não um exercício em sala de aula, mas também porque ele ganha uma experiência que conversa com o que ele faz academicamente, torna-o um aluno mais maduro, mais capaz de refletir a respeito das ideias sobre a tradução. Agora, do ponto de vista da instituição, tem outro problema: o aluno não é só alguém que está aprendendo, ele também é um produto do curso e se ele não está realmente apto a traduzir, mandá-lo fazer estágio fora pode refletir mal sobre o curso. Tem a ver com a estrutura que é mais ou menos imposta pela universidade. $\mathrm{O}$ aluno tem que fazer $\mathrm{X}, \mathrm{Y}$ e $\mathrm{Z}$ antes de fazer o que seria o núcleo do seu curso. Então, uma das nossas preocupações na reforma curricular foi justamente puxar, e já está lá na habilitação de espanhol, as atividades de prática de tradução para o início do curso e estendê-la até o fim, ou seja, do primeiro ao último semestre o aluno estaria fazendo atividade prática. Isso permitiria fazer estágios mais cedo do que no currículo antigo em que o aluno leva dois anos para chegar à primeira prática. Em geral, a demanda por estagiários no mercado é por motivos errados: é barato contratar um estagiário que talvez nem seja remunerado. No momento temos um estágio institucional que conseguimos que fosse feito obrigatoriamente fora da instituição. Durante um longo período o estágio era feito aqui, 204 internamente, às vezes dentro do próprio departamento, o que não dava ao aluno a experiência de um trabalho no mercado de tradução. Agora todos nossos alunos fazem estágio em ambiente profissional, fora da instituição e o estágio é acompanhado por um professor, que pede relatório e se encontra com os supervisores dos alunos no ambiente de trabalho. Alguns desses estágios transformam a vida do aluno. Ele deve ser colocado como um profissional em formação e ganhar atitudes de profissional durante o estágio. Sou absolutamente favorável que haja mais estágios, o problema é como garantir isso se já há insuficiência de docentes para suprir as necessidades do curso. Visitei um curso numa cidade contigua a Manchester, Salford, que tem um curso de pós-graduação em tradução com turmas bem pequenas. É um curso modular, todo mês vem um profissional do mundo da tradução, pode ser de uma empresa, do mercado financeiro, de um ministério. O profissional leciona usando os materiais de seu mundo real durante duas semanas e, na segunda parte do módulo, os professores da casa dão sequência ao trabalho iniciado pelo profissional. No período de férias, o aluno faz estágio com esses profissionais, no ambiente deles. Conversei com alunos do curso e eles estavam absolutamente satisfeitos. Para isso é preciso uma estrutura institucional muito flexível, que permita remunerar um profissional no nível do trabalho dele, ou seja, em um curso de tradução e interpretação você tem um intérprete do seu lado por duas semanas e tem que remunerá-lo suficientemente bem para justificar suas duas semanas de trabalho. $\mathrm{O}$ 
professor que oferece estágio também deve ser remunerado por orientar os alunos. Seria uma estrutura ideal, o aluno teria tudo ocorrendo ao mesmo tempo, bem orgânico. Mas aqui, com a estrutura burocrática que temos na universidade seria um inferno completo, alguém morreria tentando administrar.

A transmissão de ideologias é observada às vezes de modo tênue, quase imperceptível, caso não se esteja bastante atento a todo o contexto em que o texto se insere. Você acredita que a formação em tradução é importante para melhor captar e repassar essas ideologias, e como deveria ser feita essa formação?

MARK DAVID RIDD: Eu não sei se acredito que a formação em tradução é importante para melhor captar e repassar essas ideologias. Depende de como a tradução é ensinada, do tipo de atividade, do texto usado em sala de aula. Houve um ganho enorme dos anos 80 para cá com o surgimento da análise do discurso, que trouxe um componente de ideologia, de ideias e principalmente das formas de esconder atitudes nos textos, tornando o que é uma ideologização numa coisa natural e inevitável. Foi um ganho enorme na área da linguística que teve seu reflexo muito forte na área da tradução também. Mas não são todos os professores que trabalham ou percebem muito bem esse aspecto. É vital que um aluno de tradução perceba o jogo de poder que está por trás da publicação, em qualquer ambiente, qualquer momento, qualquer lugar. E que perceba as conveniências e inconveniências de passar isso adiante em um processo de tradução. A tradução pode ser um mero transporte dessas ideologias ou pode também se tornar um filtro e você começa a perceber claramente quando os textos carregam ideologias, pois são rejeitados pelo aluno, que se sente incomodado com o texto. Observei isso numa aula de textos jurídicos, para a qual levei um texto francamente homofóbico, em que o jurista tratava a homossexualidade como um crime. Daí, um aluno homossexual queria me proibir de usar o texto na sala de aula, na presunção de que se eu levei para a sala de aula, eu estava de acordo com o texto. Tive que argumentar bastante com ele para dizer que não. Então, ele falou "eu vou sair", e eu falei "você vai perder saindo porque eu não trouxe isso porque estou de acordo, mas porque a gente não pode traduzir só aquilo com o que concorda. Isso não é uma vida profissional, é uma vida de diletante." É muito importante que o professor explicite na hora de trabalhar os textos quais são os jogos e os componentes ideológicos, porque escolheu uma palavra e não outra. $\mathrm{O}$ mundo textual é tão variado e tão vasto que a gente faz um desserviço se o aluno sai do curso com uma experiência extremamente estreita da linguagem. Uma coisa que não fazemos bem 
ainda é trabalhar a fala espontânea no curso. Se você tiver que trabalhar algum dia com uma fala espontânea, por exemplo, em documentários, alguém entrevistado no meio da rua, e não se preparou, terá dificuldade de se expressar. Isso é muito mais difícil de traduzir do que textos que as pessoas apresentam como o cúmulo do desafio. A fala é muito mais separada entre as línguas, o que as pessoas dizem numa fala espontânea é muito mais distante de uma língua para a outra do que o que escrevem, porque a escrita é uma coisa que se aprende sistematicamente na escola. $\mathrm{E}$ as pessoas revelam muito mais impensadamente suas ideologias na fala espontânea, até por se traírem. Numa situação no Instituto Rio Branco [órgão responsável pela seleção e treinamento dos diplomatas brasileiros] estávamos traduzindo uma nota à impressa do Ministério das Relações Exteriores dos Estados Unidos, em que decidimos que a tradução, para ser aceitável como tradução oficial do Itamaraty, teria que apagar inteiramente toda a ideologia expressa no texto. A ideologia estava expressa em um desprezo textual, um texto malfeito, sem nenhum esmero, para dizer "vocês são tão insignificantes que não merecem sequer um bom texto". E o ambiente institucional do Itamaraty não permite esse desleixo. Então, ao fazer esse ajuste discursivo, toda carga 206 ideológica do texto se apagou. Isso foi um problema que eu não procurei, ele aconteceu em sala de aula e os alunos se tocaram e eu me toquei ao mesmo tempo para o quanto esse componente é importante. E faz parte do nosso trabalho dizer "e agora, o que a gente faz com isso"? Eles ficaram injuriados com a ideia de que essa carga ideológica não seria repassada na tradução, e por outro lado, eu falei "você é responsável pela tradução, aqui dentro de um departamento no órgão e vai para o site do Itamaraty. E aí?” Aí eles disseram “Ah não, aí tem que ser esse texto aqui”. Eles começaram a perceber que a coisa é bem viva, não é um problema teórico, é real. A palavra "teoria" é um pouco infeliz, poderíamos dizer "reflexões filosóficas" a respeito da tradução ou alguma coisa assim, ou alguma análise da tradução. As pessoas têm expectativas de uma teoria geral, um tamanho único que sirva para tudo e isso não funciona. O mundo da tradução é tão complexo que não tem como pensar que uma teoria vai dar cabo de todas as facetas da realidade da tradução. 
Em 2010 você escreveu um artigo intitulado "Quando o desgramado não confia, a língua alheia mete o cabrunco num bocapio: a autotradução de João Ubaldo Ribeiro”. Quais são os maiores empecilhos para uma autotradução? $O$ que se ganha e o que se perde em uma autotradução?

MARK DAVID RIDD: Esse texto foi originalmente uma apresentação oral. Pelo próprio título se vê que tem uma linguagem de um bruto interiorano no Nordeste. Tenho que dizer que a autotradução é um fenômeno raro. E, em geral, praticada por sujeitos bilíngues. O caso do [Samuel] Beckett, por exemplo, não se sabe qual texto precedeu qual, em inglês ou em francês. O outro é uma tradução ou uma reescrita do texto? Isso parte em geral de uma desconfiança do autor de que alguém seja capaz de fazer a tradução, então ele próprio acaba fazendo. Não foi o caso do João Ubaldo Ribeiro. Ele queria que o texto fosse traduzido para o inglês. A editora mandou para uma tradutora, ou tradutor, que depois de umas semanas devolveu dizendo que era impossível traduzir. Então, ele mesmo traduziu e, como não é bilíngue no sentido de ter crescido com as duas línguas, o texto traz todos os problemas normais de alguém com um excelente domínio de uma língua estrangeira, se metendo a escrever texto de literatura na outra língua. Você pode argumentar: mas não é o autor quem interpreta melhor o seu texto? Pode ser, mas nem sempre ele se lembra. Eu tive essa experiência de contato com o autor, perguntei: “O que você quis dizer com isso?”, "Olha, eu não lembro, não sei”, porque eles mesmos não conseguem recuperar qual foi a motivação para uma determinada frase no texto. Muitas vezes um bom tradutor é um intérprete tão bom quanto o autor. Agora, esse texto especificamente, acho impossível alguém fazer uma boa tradução em inglês sem ter duas coisas: entender perfeitamente essa fala regional sergipana e saber o que seria um discurso crível na outra língua. A linguagem em inglês tem que ser igualmente rica. Tem uma sequência de duas a três páginas de xingamentos ininterruptos, que é de onde vêm "bocapio" e "cabrunco". Tem que parecer uma lava de bílis saindo do indivíduo na outra língua que não vai ocorrer se não é sua língua. É muito difícil ter intuição apurada o suficiente na outra língua para fazer alguma coisa que pareça plausível. Quase sempre o autor tem um receio sobre o que pode acontecer com seu texto quando passar pela mão do tradutor. O [Milan] Kundera escrevia em tcheco e a certa altura resolveu passar a escrever em francês para não depender dos tradutores. O resultado é que desde então não produziu nenhuma obra como as que escreveu em tcheco e não tem tido o mesmo impacto das suas obras escritas em tcheco. É uma política enganosa, é uma estratégia enganosa. O tiro acabou saindo pela culatra. 
A tradução de textos com fortes marcadores culturais ou com forte influência da fala cotidiana gera, às vezes, grandes problemas e dificuldades, como, por exemplo, o termo "gerimpedra", citado por você em algumas ocasiões. Como ensinar as estratégias possíveis para resolução desses problemas a tradutores em formação?

MARK DAVID RIDD: Não tem como ensinar isso, até porque isso foi um momento de desespero pessoal meu. Eu estava com a tradução totalmente empacada porque tinha um grupo de nomes de madeiras, era um videodocumentário sobre Zanini, arquiteto da madeira, um sujeito com uma formação escolar muito básica e que aprendeu os nomes das madeiras onde elas estão, não no banco escolar, e ouvindo, não lendo. Então, o que ele ouviu foi o que ele guardou: "gerimpedra" é, na verdade, “angelim-pedra". O desespero me levou a abordar pessoas que não tinham nada a ver com tradução. Eu estava expondo uma angústia minha na banca de jornal aqui na UnB e um aluno ouviu e perguntou: "o senhor já procurou o professor fulano de tal na biologia? Ele é perito em madeira", e eu fui atrás dele. O professor não hesitou em nenhum dos casos porque ele também aprendeu originalmente lá fora e não nos livros. Tem uma experiência prática extraordinária e também tem toda aquela experiência técnica, ele tem recortes de troncos dessas árvores em gavetas na sua sala e vai lá e traz, 'parece com isso?' Ele imediatamente matou todas as charadas e me disse como é que se chamavam em inglês, porque andou pela Guiana na Amazônia e sabia como é que o pessoal de lá chama isso. Claro que eu chequei, e toda a informação que ele deu estava correta. Às vezes é difícil encontrar um especialista. E eu não estava buscando um especialista em madeira, mas o que o aluno disse: “esse professor é tarado por madeiras". E essa tara, esse gosto pela coisa em todos os ambientes, não só no acadêmico, permitiu a ele me dizer que “caicoara” é "acaricoara". Só alguém que já ouviu alguém chamando assim no meio do mato é que ia fazer essa ligação, ele tem a fala não escolarizada e também o que tem que aparecer na legenda, que é o nome correto, escrito corretamente na outra língua. Exponho essa experiência para o aluno em sala de aula, não estou levando nenhuma solução para ele, estou dizendo "use todas as armas que estão à sua disposição". A pior coisa possível para o tradutor é ser convencido, porque vai acabar pisando muito feio na bola e vai acabar ficando nu aos olhos de quem lê. A gente tem que desconfiar sempre e ter humildade para ver que a solução temporária pode não ser a melhor. É uma lição muito difícil de aprender na vida, quando você acha que está dominando o assunto, descobre que o conhecimento é muito mais sofisticado e muito menos preto no branco do que pensava. $\mathrm{O}$ aluno tem que perceber que um tradutor experiente pena para fazer tradução. Mas isso não se ensina, você expõe sua experiência e 
espera que ele se toque e não que aprenda, tem que se aperceber do que é a realidade de trabalhar com tradução. $\mathrm{O}$ aluno precisa reconhecer o que ele tem de bom, até na avaliação tento valorizar o que vejo de bom no aluno para ele crescer em relação a essa base boa que ele tem e obviamente ajustar o que não está bem. Mas por outro lado, tem que ter certo padrão de comportamento regular e evitar que o aluno se sinta num mar em fúria o tempo todo, existe um meio de você aprender a nadar, então, traduzir é muito de jogar o sujeito no mar e dizer “agora aprenda a nadar”, não é aprender a nadar na piscina. O mundo é esse, ele sempre vai te desafiar, não tem vida mansa.

Como você acha que as inovações tecnológicas estão ajudando e atrapalhando também o trabalho do tradutor?

MARK DAVID RIDD: Não adianta a gente brigar com o mundo tecnológico, ele se impõe. Se a gente pensar agora o que a Internet nos trouxe, nós estamos num mundo tão mais rico, com tanto mais acesso a informação, inclusive a informação dura, que tenha consistência, isso não existia antes. Antes você estava na mão do dicionário, se o dicionário técnico dizia que tal coisa era tal coisa você colocava na sua tradução mesmo não sendo. Hoje em dia, você tem acesso a textos reais na outra língua e tem meios de checar se isso realmente rola na outra língua ou não. É algo fenomenal se você pensa o que ainda vem por aí, por exemplo, com a linguística de corpus, com a capacidade que tem de armazenar enormes volumes de textos e extrair informações, generalizações, regras, comportamentos típicos, etc., isso é iluminador. Houve um ganho muito visível, por um lado, mas também inconvenientes. Uma das minhas preocupações é com a capacidade hoje em dia que temos de armazenar textos e traduções, é o uso da memória de tradução, que por um lado, é excelente porque você cria um padrão de comportamento tradutório sistemático em um determinado ambiente, então a tradução sai com a cara da instituição, do grupo de tradutores que trabalha, mas por outro lado, ele é um desestímulo para o repensar, porque você vê lá na sua tela, isso aqui você já traduziu e tem uma correspondência de 97\%, eu não vou fazer uma aposta nos 3\% restantes para eu parar lá “será que tem um jeito melhor para eu traduzir?", clico no "sim” e já vai automaticamente. Por outro lado, acho que todo tradutor deveria ter a experiência de olhar uma tradução que fez há dez anos e ficar espantado de como era inocente. Se ele tem a impressão de que está tudo ótimo é porque está atrofiando em termos de crescimento. Assim, o aluno tem que saber usar a tecnologia, tem que aprender a dominar a tecnologia. Os professores estão, em geral, muito atrasados em relação à tecnologia que existe de fato, muitas vezes o aluno está mais ligado 
tecnologicamente do que o professor, mas ele tem que ter a oportunidade de usar, aprender, e cabe ao professor mostrar ele que tem o lado B. Uma coisa que eu notei muito ao trabalhar com tradutores experientes, eles podem estar com 90 anos de idade, são sempre aprendizes, estão aprendendo diariamente e gostam de aprender. Uma tradutora, já uma senhora, com a qual eu trabalhei, me falou sobre uma tradução que ela fez de instruções para a montagem de um guindaste. Ela teve que ir até um canteiro de obras porque o guindaste tinha caído e tinha uma placa de ferro soldada na coluna central do guindaste com as instruções da montagem. Teve que se sujar para traduzir o texto e aprendeu um monte de coisas sobre guindastes que não sabia antes de fazer a tradução. E isso ficou como uma experiência bonita na cabeça dela, ela lembrou dessa experiência anos depois, com gosto.

O que mais te fascina na tradução?

MARK DAVID RIDD: Olha, tudo, tudo. Eu realmente tenho gosto nisso, eu gosto de traduzir quase qualquer coisa. Mas é claro, textos muito chatos e longos te deprimem. Eu não faço nenhuma tradução sem frio na barriga, sempre vou com a sensação "alguma coisa vai me 210 deixar na lona”.

\section{Você já traduz há 30 anos?}

MARK DAVID RIDD: É por aí... E eu realmente gosto do quebra-cabeça que é a tradução. Eu gosto porque é difícil, aquilo me dá um certo barato. Claro, na hora você xinga o troço, porque não está se ajustando, mas conseguir vencer aquilo é como um desafio, aquilo realmente me dá um prazer por muito tempo. Eu me lembro que penei com um refrão de uma musiquinha infantil e aquilo foi um pesadelo diário. Durante semanas e semanas eu produzia versões, voltava para o cliente, sentávamos um grupo todo falante de inglês, cantávamos a música em inglês e eu falava “ainda não está bom”. Quando eu estava passando aspirador na piscina no fim de semana, de repente me deu um clique, “A solução é essa!", e larguei o aspirador, corri para dentro para pegar um papel e escrever antes que me esquecesse, e, embora tenha sido um pesadelo durante várias semanas, quando resolvi aquilo me deu um barato por semanas a fio. Talvez seja isso que me faz ir para a sala de aula com gosto para dar aula de tradução, porque eu derivo muita felicidade de traduzir e acho que isso está visível para o aluno em sala de aula. Ele percebe que você não faz aquilo por razões burocráticas, que aquilo vai direto para o seu coração. Se eu vejo uma solução muito legal de alguém em sala de aula, fica muito claro na minha cara que aquilo me trouxe felicidade por ser uma solução para um problema desafiador. Tenho muito gosto em fazer uma revisão quando sinto que o texto 
andou muito desde sua passagem inicial para se tornar um texto por si só na outra língua. É justamente por ser difícil, imprevisível, é sempre diferente, eu nunca estou fazendo o mesmo. O pior trabalho é a sensação de rotina, uma rotina massacrante. Com tradução não vejo assim nunca, nem fazendo tradução nem lecionando, mesmo que eu leve o mesmo texto que outras turmas já fizeram para a sala de aula, ele não é o mesmo, eu não sou o mesmo. E eu sempre retomo, repenso, pesquiso mais e também procuro variar o que estou usando em sala de aula justamente para não ter essa experiência, não quero que seja algo que não me desperte a fome. Eu sempre tenho fome de fazer tradução, de me informar melhor. Então, é isso.

\footnotetext{
${ }^{1}$ Currículo Lattes em: <http://buscatextual.cnpq.br/buscatextual/visualizacv.do?id=K4799322T9>.

${ }^{2}$ Currículo Lattes em: <http://buscatextual.cnpq.br/buscatextual/visualizacv.do?id=K4235914P7〉.
} 